Bulletin d'Histoire Contemporaine de I'Espagne

$54 \mid 2020$

Les espaces du politique dans l'Espagne du Trienio liberal (1820-1823)

JOSEP FONTANA (1931-2018)

Andreu Mayayo i Artal y Universitat de Barcelona

\author{
(2) OpenEdition \\ Journals \\ Edición electrónica \\ URL: http://journals.openedition.org/bhce/3283 \\ DOI: 10.4000/bhce.3283 \\ ISSN: 1968-3723 \\ Editor \\ Presses Universitaires de Provence
}

Edición impresa

Fecha de publicación: 1 enero 2020

ISSN: 0987-4135

Referencia electrónica

Andreu Mayayo i Artal y Universitat de Barcelona, « JOSEP FONTANA (1931-2018) », Bulletin d'Histoire Contemporaine de l'Espagne [En línea], 54 | 2020, Publicado el 01 julio 2020, consultado el 02 enero

2021. URL : http://journals.openedition.org/bhce/3283; DOI : https://doi.org/10.4000/bhce.3283

Este documento fue generado automáticamente el 2 enero 2021.

Bulletin d'histoire contemporaine de l'Espagne 


\section{JOSEP FONTANA (1931-2018)}

\section{Andreu Mayayo i Artal y Universitat de Barcelona}

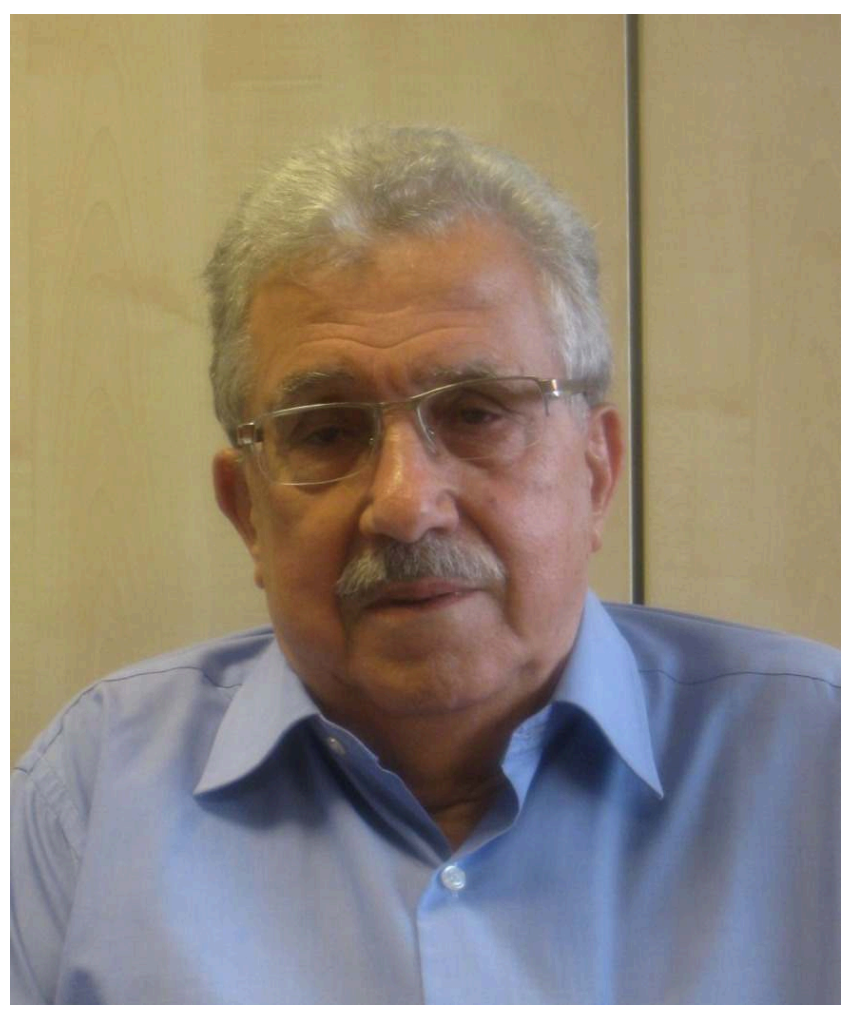

CArchivo BHCE

2 Josep Fontana i Lázaro (Barcelona, 1931-2018) fue uno de los más ilustres ciudadanos de honor de la república de las letras engendrado, amamantado y casi sepultado (por los bombardeos fascistas), en la librería familiar de la calle de la Palla en pleno barrio Gótico, a tiro de piedra del Palau de la Generalitat. El historiador catalán más influyente en la historiografía española y latinoamericana era una biblioteca ambulante en la triple dimensión de lector, editor y escritor. Alfabetizado a través de la letra impresa, Fontana fue un militante de la Historia, a la que se dedicó en cuerpo y alma como si fuera un sacerdocio, convencido que era un arma, en manos de los sectores populares, 
cargada de razones para el futuro. La Historia enseña pero no tiene alumnos, sentenciaba Antonio Gramsci. No obstante, en el caso de Josep Fontana, dejó una numerosa tropa de discípulos.

3 Todo empezó a los seis años cuando, tras una bomba dirigida contra la sede del gobierno catalán destrozaba la librería (aunque peor suerte tuvieron los niños muertos en el vecino refugio de la iglesia de Sant Felip Neri), su padre le regaló los primeros cinco libros (en catalán) de su biblioteca y que, después de una larga y fructífera vida, consiguió multiplicarlos por diez mil hasta redondear los 50.000 volúmenes y folletos algunos difíciles de encontrar como las actas del Segundo Congreso Obrero de la Sección Española de la Internacional, celebrado en Zaragoza en el año 1872-, que donó generosamente a la Universitat Pompeu Fabra, la universidad pública creada por la Generalitat en el año 1990 donde fundó y dirigió el Instituto Jaume Vicens i Vives.

El profesor Jaume Vicens, que consiguió regresar en el año 1948 como docente a la Universidad de Barcelona, era una isla de modernidad en un mar de retrógrados en la universidad franquista de los años cincuenta. El joven y dinámico catedrático de Historia Moderna y Contemporánea, que al año siguiente crearía el Centro de Estudios Históricos Internacionales (CEHI), con una clara vocación de superar la autarquía intelectual impuesta por la Dictadura, le conectó con la escuela de los Annales (a la revista de la cual se subscribió en el año 1955 y se mantuvo fiel toda la vida, aunque en los últimos años la leía con una cierta desidia), que renovó la historiografía económica a partir de la introducción de la estadística. Además Vicens, con una clara vocación de trascender el estricto marco universitario, le inculcó la conciencia cívica de servicio público a través de la ciencia histórica.

5 Cuando Vicens se dio cuenta que ya no podía satisfacer el hambre intelectual de su discípulo, le encaminó hacía Pierre Vilar, con el cual no tan sólo hablaban de Historia sino de lo que ocurría en el mundo y, por supuesto, de su fe en el comunismo. Del historiador marxista francés apreciaba su reflexión sobre el concepto de Historia de Karl Marx a partir de los primerizos escritos (junto con Engels) recopilados en La ideología alemana (1845-46, aunque no publicada hasta 1932) más que del esquematismo excesivamente simplista del prefacio a la Contribución a la crítica de la economía política (1859). Mientras en la filosofía las ideas van del cielo a la tierra en la Historia (la filosofía de la praxis, en términos marxistas) se parte de la vida real de los hombres para llegar a sus pensamientos. Toda vida social, escribía Marx, es esencialmente práctica. La Historia se fundamenta en los hechos y no en los relatos, aunque la interpretación es libre tal como Fontana dejó escrito en la Historia de los hombres (2000, en versión original catalana; 2005, en versión castellana). Continuación de sus afamadas reflexiones historiográficas vertidas en sus conferencias dirigidas a los profesores de secundaria y publicadas en libros como Historia: análisis del pasado y proyecto social (1982) y La història després de la fi de la història (1992).

6 Fontana siempre vindicó como maestros a Vicens i Vives, Pierre Vilar y, más tardíamente, Ferran Soldevila quien, depurado por el franquismo, seguía impartiendo sus clases en el comedor de su casa y a las que asistió Fontana en su época de estudiante en busca de refugio intelectual, democrático y catalanista, durante tres años. Soldevila, etiquetado como historiador romántico, era el autor de Història de Catalunya (en tres volúmenes), que le regaló su padre y que siempre conservó con devoción. De él, decía, aprendió que tras un documento hay seres humanos con sentimientos y problemas. Un factor más ligaría Fontana con Soldevila, su lectorado en la Universidad de Liverpool. 
Soldevila había ocupado la plaza de lector de estudios hispánicos en los años 1926-1928 y, treinta años después, tras licenciarse, lo haría Fontana, quién no sólo tuvo acceso a una bibliografía inimaginable sino que se familiarizó con las estructuras narrativas historiográficas anglosajonas alejadas del academicismo francés. Así mismo, entró en contacto con el Grupo de Historiadores del Partido Comunista Británico a través de la revista Past and Present, creada en el año 1952 y liderada por Christopher Hill y Eric Hobsbawm. Fontana sería, a través de su amigo y editor Gonzalo Pontón, el principal introductor del marxismo británico en nuestro país.

7 De vuelta de Liverpool y ajeno a la ruptura del grupo de historiadores comunistas y de la disidencia de muchos intelectuales en toda Europa que había provocada la intervención de las tropas soviéticas en Budapest mientras el mundo libre miraba estremecido hacía el Canal de Suez, Fontana vencía su proverbial timidez y tuvo el coraje de tomar Partido. En plena noche franquista y Guerra Fría, en el año 1957, el camarada Rosell se incorporaba a la célula comunista de intelectuales del Partit Socialista Unificat de Catalunya (PSUC) colaborando estrechamente en la revista clandestina Nous Horitzons en los años sesenta y setenta. A menudo las reuniones, frecuentadas también por los historiadores Josep Termes, Ramon Garrabou y Miquel Izard, se celebraban en casa de sus padres bajo la atenta mirada de su progenitor, que recordaba los tiempos en que su librería acogía las reuniones de jóvenes militantes del Bloque Obrero y Campesino. Fontana creció en una familia catalanista y de izquierdas, que ligaba los derechos sociales y los nacionales de Cataluña. Y, en este sentido, el PSUC era la organización que mejor los encarnaba. Fontana empezó su militancia política a la par de su actividad docente. Jaume Vicens se lo llevó de profesor ayudante, junto con otros discípulos, a la recién creada Facultad de Económicas, en la que impartió clases hasta su expulsión en el año 1966 como consecuencia de su apoyo a la constitución del Sindicato Democrático de Estudiantes de la Universidad de Barcelona (SDEUB), en la famosa Capuchinada.

8 El destierro académico, durante el cual empezó a trabajar en la editorial Ariel y a dirigir la sección de Historia de la Larousse, duró dos años hasta que pudo entrar en la neonata Universidad Autónoma de Barcelona (UAB). Su labor investigadora se centró en la historia económica de la España del siglo XIX y en el tránsito del Antiguo Régimen al Estado liberal y la sociedad burguesa, al que dedicó su tesis doctoral, defendida el año 1970, y sus primeros libros La quiebra de la monarquía absoluta (1814-1820) (1971) y Cambio económico y actitudes políticas en la España del siglo XIX (1973). Así mismo, contribuyó al nacimiento de la revista Recerques (1970), que supuso una renovación de la historiografía catalana dando a conocer las investigaciones, muchas de ellas fruto de tesis doctorales, de la emergente y pujante generación de historiadores e historiadoras. En el año 1974 conseguiría la cátedra de Historia Económica en la Universidad de Valencia y dos años después regresaría a la $\mathrm{UAB}$, donde fue decano y vicerrector, hasta recalar en el año 1991 en la también neonata Universitat Pompeu Fabra, donde se jubilaría en 2001 aunque continuaría prestando sus servicios como emérito.

9 Una vez despojado de la túnica y el birrete académico, Fontana en cierta medida se desmelenó y pasó del siglo XIX al siglo XX y XXI, de la historia económica a la historia política y del manual universitario al relato de alta divulgación. Siguiendo a su admirado Hobsbawm, nos ha legado unas extraordinarias síntesis históricas, de visión enciclopédica, a partir de fuentes secundarias, mayoritariamente de bibliografía en inglés, en las que destacan Por el bien del imperio. Una historia del mundo desde 1945 (2011) 
y El siglo de la revolución: una historia del mundo de 1914 a 2017 (2017). La tesis que defiende Fontana es que el gran conflicto global que dominó la segunda mitad del siglo XX no fue el enfrentamiento del "mundo libre" contra "el comunismo", como se nos ha contado, sino el de las fuerzas armadas de "la libertad de empresa" contra todo aquello que podía oponerse a sus intereses, disfrazado como una cruzada contra los restos del viejo proyecto socialista soviético, que ya no era capaz de llevar más adelante la transformación de la sociedad, y aspiraba a poco más que a sobrevivir a las amenazas externas y a mantener el orden social interno con métodos autoritarios. La amenaza no eran la URSS y sus satélites, sino la capacidad que podían conservar las viejas ideas para oponerse a los abusos del capitalismo.

10 Con motivo del tricentenario de la derrota de 1714, Fontana publicó un libro de matriz thompsoniana (por E. P. Thompson) titulado La formació d'una identitat. Una historia de Catalunya (2014), donde centraba su atención en el papel clave de las clases populares en la pervivencia de una identidad nacional catalana ante los intentos de asimilación tras tres guerras perdidas (1652, 1714 y 1939) y los largos períodos de represión cultural. L'agit-prop independentista, en pleno auge en Cataluña, intentó apropiarse de la figura venerable de Josep Fontana -como Ronald Reagan hizo con el Born in the USA de Bruce Springsteen - lo que le obligó a marcar distancias del nacionalismo liberal gobernante alumno aventajado de las políticas de austeridad y de recortes sociales. Fontana había abandonado su militancia orgánica en el año 1980 aunque siguió dando su apoyo público (y, por supuesto, crítico) al PSUC y, su sucesora, Iniciativa per Catalunya Verds. Así mismo, mantuvo siempre un vínculo muy estrecho con el sindicalismo de Comisiones Obreras. Para dejar clara su posición política aceptó, por primera vez, figurar en una candidatura electoral, concretamente en las elecciones municipales de 2015 cerrando la lista de Barcelona en Comú, que encabezada la futura alcaldesa Ada Colau.

11 Fontana no hacía ascos a la posibilidad de una Catalunya independiente pero le sacaba de quicio la hoja de ruta del "todo o nada" y del "ahora o nunca". Por eso no cayó en la trampa de la naturaleza plebiscitaria otorgada por el Gobierno de la Generalitat a las elecciones autonómicas de 2015 y, mucho menos, en el apoyo de una vía unilateral de confrontación contra España sin la complicidad de la Unión Europea. Sabía mejor que nadie que las secesiones sin acuerdo y mediación internacional se ahogan en sangre. Por este motivo se negó a firmar el manifiesto de antiguos militantes de izquierdas que pedían el voto para las candidaturas independentistas. Cuando le preguntaron en su último acto público (noviembre de 2017) si Cataluña estaba viviendo una revolución, Fontana respondía que si el llamado "procés" "pretendía ser una revolución, de momento era una revolución frustrada. Contemplo la DUI (Declaración Unilateral de Independencia) como una catástrofe y desde el más absoluto desacuerdo. Estamos en un momento de aprender a resistir, a no resignarnos, a salir adelante y tratar de recuperar lo que podamos de nuestros derechos y libertades ya de por si suficientemente amenazados.

12 Fontana nos espoleó a ser críticos con el poder establecido y aprender de las derrotas para poder ganar algún día. Leerlo no es tan sólo la mejor manera de mantenerlo vivo sino de seguir aprendiendo para mejorar nuestro quehacer historiográfico $\mathrm{y}$, sin duda alguna, nuestro compromiso cívico. Fiel a su concepto que la Historia ha de ser un análisis crítico de los acontecimientos y que su estudio debe ayudar a crear una conciencia de la Historia, en la pared de su estudio, repleto de libros, colgaba un poema 
escrito por Bertolt Brecht en los años treinta del siglo XX titulado Loa de la dialéctica, deudor de una poderosa y sugerente imagen del Manifiesto Comunista: Todo lo sólido se desvanece en el aire. Y que, de algún modo, él con su labor había dado sentido.

Con paso firme se pasea hoy la injusticia.

Los opresores se disponen a dominar otros diez mil años más.

La violencia garantiza: « Todo seguirá igual ».

No se oye otra voz que la de los dominadores,

y en el mercado grita la explotación: « Ahora es cuando empiezo ».

Y entre los oprimidos, muchos dicen ahora:

"Jamás se logrará lo que queremos".

Quien aún esté vivo no diga " jamás ».

Lo firme no es firme.

Todo no seguirá igual.

Cuando hayan hablado los que dominan,

hablarán los dominados.

¿Quién puede atreverse a decir « jamás »?

¿De quién depende que siga la opresión? De nosotros.

¿De quién que se acabe? De nosotros también.

¡Que se levante aquel que está abatido!

¡Aquel que está perdido, que combata!

¿Quién podrá contener al que conoce su condición?

Pues los vencidos de hoy son los vencedores de mañana

y el jamás se convierte en hoy mismo. 